\title{
EUS-Guided versus Percutaneous Image-Guided Liver Biopsy: A Battle for Supremacy!
}

\author{
Shubhra Mishra ${ }^{1} \quad$ Nikhil Bush ${ }^{1} \quad$ Surinder S. Rana ${ }^{1}$ \\ ${ }^{1}$ Department of Gastroenterology, Post Graduate Institute of \\ Medical Education and Research (PGIMER), Chandigarh, India
}

\begin{abstract}
Address for correspondence Surinder Singh Rana, MD, DM, Department of Gastroenterology, PGIMER, Sector 12, Chandigarh 160 012, India (e-mail: drsurinderrana@gmail.com).
\end{abstract}

J Digest Endosc 2021;12:120-124.

\begin{abstract}
Keywords

- endoscopic ultrasound

- liver biopsy

- ultrasound

- bleeding

Liver biopsy has been the gold standard investigation for diagnosing and staging liver diseases. Image-guided percutaneous liver biopsy is a time-tested technique for obtaining the liver tissue in diffuse liver diseases. However, it is contraindicated in patients with ascites, altered mental status, skin infections, coagulopathy, and thrombocytopenia. It is associated with adverse events including postprocedure pain, bleeding, and pneumothorax. Transvenous liver biopsy can be performed in most cases with these contraindications, but it is an expensive technique and has its own inherent risks. Endoscopic ultrasound (EUS)-guided liver biopsy (EUS-LB) is a relatively new technique that has shown promising results and seems to have a potential of replacing percutaneous liver biopsy. In this news and views, we discuss the results of a randomized controlled trial (RCT) comparing EUS-guided and percutaneous techniques of liver biopsy. This RCT reported that percutaneous technique is superior in terms of diagnostic adequacy and total expenditure without any significant adverse effects compared with EUS-LB. EUS-LB is a promising technique that needs to be further explored in terms of appropriate situations in which it can be preferred over percutaneous or transvenous routes.
\end{abstract}

\section{Introduction}

The liver is a unique organ, as it derives its blood supply from both the systemic arterial and portal venous systems. Liver parenchyma can be diffusely involved in storage disorders, infiltrative diseases and metabolic abnormalities, and in patients with chronic liver disease, with or without cirrhosis. Despite the ever-expanding list of noninvasive investigations, liver biopsy still serves as a "gold standard" test for evaluating liver parenchymal diseases. ${ }^{1}$ Liver biopsy can be targeted when a specific lesion needs to be biopsied, or it can be untargeted when done for conditions with diffuse hepatic involvement. Along with its diagnostic role, liver biopsy can also be used to assess the severity or stage a liver disease. ${ }^{2}$
The first liver biopsy was performed in 1883 by Paul Ehrlich. ${ }^{3}$ Thereafter, with time, the technique of liver biopsy has evolved from a blind to a real-time, imaging-guided procedure. ${ }^{4}$ However, despite being image guided, percutaneous liver biopsies are not without complications. Post-biopsy complication rates can vary from 0.3 to $3.3 \%$. Most common complications are postprocedure pain, and bleeding that can occur in up to $10.9 \%$ of patients. Percutaneous liver biopsy is contraindicated in patients with ascites, coagulopathy and local site infection and uncooperative patients. ${ }^{5,6}$ Transvenous (transjugular) liver biopsy was added to the armamentarium in 1973 as an alternative to percutaneous biopsy in patients with ascites or coagulopathy. ${ }^{7}$
DOI https://doi.org/ $10.1055 / \mathrm{s}-0041-1731865$ ISSN 0976-5042 (c) 2021. Society of Gastrointestinal Endoscopy of India.

This is an open access article published by Thieme under the terms of the Creative Commons Attribution-NonDerivative-NonCommercial-License, permitting copying and reproduction so long as the original work is given appropriate credit. Contents may not be used for commercial purposes, or adapted, remixed, transformed or built upon. (https://creativecommons.org/licenses/by-nc-nd/4.0/).

Thieme Medical and Scientific Publishers Pvt. Ltd. A-12, 2nd Floor, Sector 2, Noida-201301 UP, India 
Endoscopic ultrasound (EUS) has been found to be useful in diagnosing and treating a variety of hepatic conditions, including focal hepatic lesions (such as focal nodular hyperplasia, regenerative nodular hyperplasia, and hemangioma), simple hepatic cysts, abscesses, and portal hypertension. ${ }^{8}$ The major limitations of EUS include limited visualization of the right and caudate lobes and increased risk of complications in patients with altered anatomy, in additions to the risk of EUS-fine-needle aspiration (FNA) such as bleeding and perforations. ${ }^{9}$ There is ample evidence to support the use of contrast-enhanced, EUS-guided coiling and glue injection in the treatment of gastric or ectopic varices associated with portal hypertension. ${ }^{10}$ The use of contrast-enhanced, harmonic EUS has, therefore, further widened the horizon of indications and enhanced diagnostic performance of EUS in these conditions. The advent of EUS-guided liver biopsy (EUS-LB) in recent years has further widened the ever expanding diagnostic and therapeutic potential of EUS in liver diseases.

EUS-LB was introduced in 2005. ${ }^{11}$ It was performed using a $19 \mathrm{G}$ tru-cut biopsy needle. While the specimens yielded were small (median complete portal tract $=2$ ), a diagnosis was reached in $90 \%$ cases. Since then, there have been many improvements in the needle used to perform EUS-LB. ${ }^{12}$ 19 G FNB needles were found to be more effective than FNA needles, in terms of adequacy of the sample. They have now come into standard practice for EUS-LB. EUS-LB offers certain advantages over percutaneous biopsy, including easy access to both lobes, easy access in obese or pregnant patients, and decreased postprocedure pain. ${ }^{13}$ Since EUS-LB is performed under sedation, it can be done with ease in pediatric population. ${ }^{14}$ Furthermore, the procedure can be done in the same sitting when performing a diagnostic EUS for evaluation of jaundice or liver pathology.

Clinical usefulness of a liver biopsy depends on the adequacy of the sample obtained. British Society of Gastroenterology published a guideline on liver biopsy in 2020 and stated that for a liver biopsy sample to be deemed adequate, it should be at least $20 \mathrm{~mm}$ in length and should contain 11 or more complete portal triads (CPT). ${ }^{2}$ The yield of a procedure for an adequate liver biopsy specimen depends on multiple factors, including the type of needle being used, with fine needle biopsy needles being more efficacious than aspiration needles, the caliber of the needle used (19 G better), degree of tissue fragmentation, and architectural distortion. ${ }^{12,15,16,17}$

The adequacy and clinical safety of EUS-LB and percutaneous liver biopsy have been compared in many retrospective studies previously. Pineda et al compared the total specimen length and CPT in biopsies taken using percutaneous route (18 or $20 \mathrm{G}$ needle), transjugular route (18 or $19 \mathrm{G}$ needle), and EUS guided transgastric/transduodenal route (19 G FNA needle). They found that EUS-guided biopsy yielded a longer total specimen when both lobes were biopsied and concluded that EUS-LB yields specimens at least comparable to, and in some cases better than, percutaneous or transjugular liver biopsy..$^{18}$ Shuja et al retrospectively compared the adequacy of EUS-LB done using a 19 G FNA needle with percutaneous and transvenous liver biopsy. While the total specimen length was longest for EUS route, maximum number of CPT were seen with percutaneous biopsy. This disparity was attributed to the wider gauge of needles used for percutaneous biopsy. Importantly, significant postprocedure complications were seen more commonly with image-guided biopsies $(p=0.03) .{ }^{19}$ Ali et al conducted a retrospective study comparing the efficacy of EUS-LB when using a 19 or 22 G Fork-tip SharkCore biopsy needle with percutaneous liver biopsy. Median core length and number of portal tracts was higher per sample with percutaneous route. However, EUS-LB was associated with a shorter hospital stay and need for analgesics. ${ }^{20}$ In another retrospective study, Bhogal et al found the safety profile, technical success rate, and diagnostic adequacy of all three routes to be similar ( - Table 1). ${ }^{21}$ Despite having so many published studies on the topic of EUS-LB, there has been no randomized controlled trial (RCT) conducted to date to compare the efficacy of liver biopsy using percutaneous and EUS-guided transgastric/transduodenal route. In this edition of "News and Views," we shall discuss the first RCT conducted by Bang et al, which was first published online in Gut on March 25, 2021.22

In this study, consecutive patients eligible for the trial were recruited between July 2019 and November 2020. Patients with mass lesions and those with irreversible coagulopathy were excluded from the trial. Estimated sample size was 34 (17 patients in each group) and randomization was implemented using block randomization method with a 1:1 allocation ratio. Patients were randomized to either percutaneous or EUS-LB. It was impossible to blind the patients or the performing physicians to the procedure. However, the reporting pathologists and the outcome investigators were blinded. EUS-LB was performed using linear array echoendoscopes under propofol sedation $(n=21)$. 19G FNB needle was used and biopsy was obtained without suction or fanning, with two passes per patient from either lobe of liver and specimen from each pass sent separately. Right lobe biopsy was performed only if no suitable site was available in the left lobe. A maximum of 10 to-and-fro needle movements were performed during each pass, but in most patients, it was confined to less than five to-and-fro movements. Percutaneous biopsy was performed using a $16 \mathrm{G}$ Biopince needle $(n=19)$ and the need for sedation was left at the discretion of the treating physician. Single specimen was obtained per patient and all specimens were sent for processing in containers filled with $10 \%$ formalin. Optimal specimens were defined as length of $>25 \mathrm{~mm}$ after fixation and presence of 11 or more CPT. The primary outcome was to compare the rate of procurement of optimal specimens. Secondary outcomes included comparison of maximum specimen length, total number of CPT, duration of procedure, adverse effects, pain scores, and procedural costs.

While final diagnosis was made with all the specimens, more optimal specimens were obtained with percutaneous route $(57.9 \%$ vs. $23.8 \% ; p=0.028)$. Although the number of CPT were similar, the median specimen length obtained was longer with percutaneous route (26 mm vs. $16.5 \mathrm{~mm}$; $p=0.004)$. Moreover, a final diagnosis was obtained on all 
Table 1 Synopsis of studies on EUS-LB

\begin{tabular}{|c|c|c|c|c|c|c|}
\hline Author & \multirow[t]{3}{*}{ Procedure (n) } & \multirow[t]{3}{*}{ Needle used } & \multirow[t]{3}{*}{ Technique } & \multirow{3}{*}{$\begin{array}{l}\text { Total specimen } \\
\text { length }(\mathrm{mm})\end{array}$} & \multirow[t]{3}{*}{ CPT } & \multirow[t]{3}{*}{ Adverse events ( $n$ ) } \\
\hline Year & & & & & & \\
\hline Study type & & & & & & \\
\hline Shuja et al ${ }^{19}$ & \multirow[t]{3}{*}{ EUS-LB (69) } & $\begin{array}{l}19 \text { G FNA needle } \\
\text { (Expect Flexible; }\end{array}$ & Saline primed & \multirow[t]{3}{*}{$45.8(20.7)$} & \multirow[t]{3}{*}{$10.84(7.23)$} & \multirow[t]{3}{*}{0} \\
\hline 2019 & & Boston Scientific) & Suction + & & & \\
\hline \multirow[t]{3}{*}{ Retrospective } & & & 3 passes & & & \\
\hline & \multirow[t]{2}{*}{ PCLB (47) } & \multirow[t]{2}{*}{$18 \mathrm{G}$ needle } & Right lobe & \multirow[t]{2}{*}{$43(13.4)$} & \multirow[t]{2}{*}{$15.9(6.74)$} & \multirow{2}{*}{$\begin{array}{l}\text { Pneumothorax (1), } \\
\text { HA pseudoaneu- } \\
\text { rysm(1), pain (4) }\end{array}$} \\
\hline & & & 2-3 passes & & & \\
\hline Pineda et al $^{18}$ & \multirow[t]{2}{*}{ EUS-LB (110) } & \multirow{2}{*}{$\begin{array}{l}19 \text { G FNA needle } \\
\text { (Expect } \\
\text { or Expect Flexible; } \\
\text { Boston Scientific) }\end{array}$} & Suction + & \multirow[t]{2}{*}{$38(24-81)$} & \multirow[t]{2}{*}{$14(9-27)$} & \multirow[t]{2}{*}{ NA } \\
\hline \multirow[t]{2}{*}{ Retrospective } & & & $\begin{array}{l}\text { 2-3 passes; 7-10 } \\
\text { actuation /pass } \\
\text { 2nd lobe biopsy } \\
\text { depending on } \\
\text { endoscopist } \\
\text { discretion }\end{array}$ & & & \\
\hline & PCLB (27) & $\begin{array}{l}\text { 18-gauge, } \\
\text { 19-gauge, or } \\
\text { 20-gauge needle } \\
\text { (Coaxial Temno } \\
\text { Needle [CT-2015]) }\end{array}$ & $\mathrm{NA}$ & $25(15-18)$ & $10(7-16)$ & NA \\
\hline Ali et $\mathrm{al}^{20}$ & \multirow[t]{3}{*}{ EUS-LB (30) } & $19-$ & $\begin{array}{l}\text { Heparin flush; } \\
\text { suction + }\end{array}$ & \multirow{3}{*}{$\begin{array}{l}25 \\
\text { Fragmentation } \\
\text { in } 40 \%\end{array}$} & \multirow[t]{3}{*}{5} & \multirow[t]{3}{*}{ Pain (1) } \\
\hline \multirow[t]{3}{*}{ Retrospective } & & \multirow{2}{*}{$\begin{array}{l}\text { or } 22 \text {-gauge } \\
\text { Fork-tip SharkCore } \\
\text { biopsy needle } \\
\text { (Medtronic) }\end{array}$} & Either lobe biopsied & & & \\
\hline & & & $\begin{array}{l}2 \text { passes-2-3 } \\
\text { actuations/pass }\end{array}$ & & & \\
\hline & PCLB (60) & $\begin{array}{l}18 \text { G CorVocet nee- } \\
\text { dle (Meritmedica) }\end{array}$ & NA & $\begin{array}{l}31 \\
\text { Fragmentation } \\
\text { in } 10 \%\end{array}$ & 13 & 0 \\
\hline Bhogal et al ${ }^{21}$ & \multirow[t]{2}{*}{ EUS-LB (135) } & $19-G$ & \multirow[t]{2}{*}{ NA } & \multirow[t]{2}{*}{$34.7(100)$} & \multirow[t]{2}{*}{$19.7(10)$} & \multirow{2}{*}{$\begin{array}{l}\text { Pain (1), 30-day mor- } \\
\text { tality (1) }\end{array}$} \\
\hline \multirow[t]{2}{*}{ Retrospective } & & $\begin{array}{l}\text { needle (Expect } \\
\text { FNA } 2013 \text { to } 2017, \\
\text { Acquire FNB } 2017 \\
\text { to } 2019 \text { Boston } \\
\text { Scientific) }\end{array}$ & & & & \\
\hline & PCLB (287) & NA & NA & $29.2(90)$ & $17.4(9)$ & Pain (1); bleeding (1) \\
\hline Bang et al 22 & EUS-LB (21) & 19-G FNB needle & Suction - & $19.2(6.9)$ & $>10$ in 17 & 0 \\
\hline RCT & & $\begin{array}{l}\text { (Acquire, Boston } \\
\text { Scientific) }\end{array}$ & Max 10 passes & & $(81 \%)$ & \\
\hline & & & $\begin{array}{l}2 \text { passes. Right lobe } \\
\text { biopsy if no suitable } \\
\text { site in left }\end{array}$ & & & \\
\hline & PCLB (19) & $\begin{array}{l}\text { 16-gauge biopsy } \\
\text { needle (Biopince) }\end{array}$ & $\begin{array}{l}1 \text { core obtained. } \\
\text { Second pass if no } \\
\text { specimen on } 1 \mathrm{st}\end{array}$ & $25.9(4.3)$ & $\begin{array}{l}>10 \text { in } 18 \\
(94.7 \%)\end{array}$ & 0 \\
\hline
\end{tabular}

Abbreviations: CPT, complete portal tract; EUS-LB, endoscopic ultrasound-guided liver bioscopy; FNA, fine-needle aspiration; FNB, fine-needle biopsy; PCLB, percutaneous liver biopsy; RCT, randomized control trial.

single pass biopsy specimens procured percutaneously, whereas in two of 21 patients in EUS group, specimens from both passes had to be assessed cumulatively to obtain the final diagnosis. There were no adverse events in either group. Postprocedure visual analog scale (VAS) score for pain was higher for percutaneous method at 1 hour but similar thereafter and the total mean cost accrued was significantly higher with the EUS method.

\section{Commentary}

The authors of the study need to be lauded for the innovative and paradigm-changing RCT that was eagerly awaited. While the diagnostic yield of liver biopsy by both methods was similar, percutaneous method appears to be more appropriate when the objective of the biopsy was to assess the severity and stage the disease. Authors speculate that likely reason 
for superiority of percutaneous method is the design of EUS needles, which are not a fully core obtaining needles in contrast to percutaneous needles, and the fact that FNB needle tip is partially flexed, as it is moves back and forth in different trajectories during EUS guidance, whereas the percutaneous needle uses a single-cut motion in a straight plane. Moreover, the authors found that the EUS-based approach was more costly with longer procedural duration, and there was no added advantage in safety profile.

Image-guided percutaneous liver biopsy is the workhorse for decades and has performed very well in daily clinical practice. The added advantage of percutaneous method is that it is widely available, does not need special expertise, and is cheaper. Because of the inherent properties, EUS-guided methods is going to be expensive, less widely available, and will need special expertise. Therefore, to be widely advocated, it needs to perform better than percutaneous method in diagnostic yield and safety profile. Moreover, any added information it provides would tilt the balance toward EUS-LB. Previous retrospective comparative studies have reported similar diagnostic yield as well as safety profile of both the procedures, and the current RCT has confirmed these results. Moreover, tissue fragmentation has been a concern with EUS-LB, and this RCT has confirmed that the quality of liver biopsy obtained with percutaneous method is better than EUS-LB. The only advantage of EUS-LB in the current RCT seems to be lesser pain scores postprocedure.

Theoretically, additional advantages of EUS approach could be simultaneous evaluation of pancreas, gallbladder, common bile duct, and other structures along with concurrent endoscopy to evaluate for varices. However, the clinical and cost implications of this additional information need to be prospectively studied. EUS-guided portal pressure measurement is a promising tool for evaluation of patient with liver diseases and could make EUS-guided approach a one-stop diagnostic tool. ${ }^{23}$ In the present clinical practice, percutaneous liver biopsy seems to be a better option. However, there seems to be a cohort of patient who would benefit from EUS-guided procedures specifically (based on pain sensitivity, body habitus, need for concomitant endoscopy, and both lobe biopsy).

\section{Author Contributions}

1. Shubhra Mishra: drafting of manuscript.

2. Nikhil Bush: drafting of manuscript.

3. Surinder Singh Rana: critical evaluation of manuscript.

\section{Conflicts of Interest}

There are no conflicts of interest and no financial disclosures to be made by any of the authors.

\section{References}

1 Caldwell S. Liver biopsy: the reports of its demise are greatly exaggerated. Clin Transl Gastroenterol 2016;7:e171

2 Neuberger J, Patel J, Caldwell H, et al. Guidelines on the use of liver biopsy in clinical practice from the British Society of Gastroenterology, the Royal College of Radiologists and the Royal College of Pathology. Gut 2020;69(8):1382-1403
3 Von Frerichs FT. Ueber den Diabetes. Berlin: Hirschwald; 1884

4 Caturelli E, Giacobbe A, Facciorusso D, et al. Percutaneous biopsy in diffuse liver disease: increasing diagnostic yield and decreasing complication rate by routine ultrasound assessment of puncture site. Am J Gastroenterol 1996;91(7):1318-1321

5 Tian G, Kong D, Jiang T, Li L. Complications after percutaneous ultrasound-guided liver biopsy: a systematic review and meta-analysis of a population of more than 12,000 patients from 51 cohort studies. J Ultrasound Med 2020;39(7):1355-1365

6 Midia M, Odedra D, Shuster A, Midia R, Muir J. Predictors of bleeding complications following percutaneous image-guided liver biopsy: a scoping review. Diagn Interv Radiol 2019;25(1):71-80

7 Rosch W. Chronic inflammatory bowel disease and its drug therapy. PZ Prisma 1997;4(4):225-230

8 Rana SS, Ahmed S, Sharma R, Gupta R. Safety and efficacy of EUS-guided drainage of liver abscess: A single-center experience. Endosc Ultrasound 2020;9(5):350-351

9 Saraireh HA, Bilal M, Singh S. Role of endoscopic ultrasound in liver disease: Where do we stand in 2017? World J Hepatol 2017;9(24):1013-1021

10 Rana SS, Sharma R, Dhalaria L, Gupta R. Contrast-enhanced endoscopic ultrasound-guided coil and glue injection for bleeding gastric/ectopic varices. Techniques and Innovations in Gastrointestinal Endoscopy 2021;(e-pub ahead of print). doi: $10.1016 /$ j.tige.2021.01.001

11 Dewitt J, McGreevy K, Cummings O, et al. Initial experience with EUS-guided Tru-cut biopsy of benign liver disease. Gastrointest Endosc 2009;69(3 Pt 1):535-542

12 Schulman AR, Thompson CC, Odze R, Chan WW, Ryou M. Optimizing EUS-guided liver biopsy sampling: comprehensive assessment of needle types and tissue acquisition techniques. Gastrointest Endosc 2017;85(2):419-426

13 Diehl DL. Endoscopic ultrasound-guided liver biopsy. Gastrointest Endosc Clin N Am 2019;29(2):173-186

14 Johal AS, Khara HS, Maksimak MG, Diehl DL. Endoscopic ultrasound-guided liver biopsy in pediatric patients. Endosc Ultrasound 2014;3(3):191-194

15 Colombo $M$, Del Ninno $E$, de Franchis $R$, et al. Ultrasound-assisted percutaneous liver biopsy: superiority of the Tru-Cut over the Menghini needle for diagnosis of cirrhosis. Gastroenterology 1988;95(2):487-489

16 Hall TC, Deakin C, Atwal GS, Singh RK. Adequacy of percutaneous non-targeted liver biopsy under real-time ultrasound guidance when comparing the Biopince and Achieve biopsy needle. Br J Radiol 2017;90(1080):20170397

17 Ching-Companioni RA, Diehl DL, Johal AS, Confer BD, Khara HS. 19G aspiration needle versus 19G core biopsy needle for endoscopic ultrasound-guided liver biopsy: a prospective randomized trial. Endoscopy 2019;51(11):1059-1065

18 Pineda JJ, Diehl DL, Miao CL, et al. EUS-guided liver biopsy provides diagnostic samples comparable with those via the percutaneous or transjugular route. Gastrointest Endosc 2016;83(2):360-365

19 Shuja A, Alkhasawneh A, Fialho A, et al. Comparison of EUS-guided versus percutaneous and transjugular approaches for the performance of liver biopsies. Dig Liver Dis 2019;51(6):826-830

20 Ali AH, Panchal S, Rao DS, et al. The efficacy and safety of endoscopic ultrasound-guided liver biopsy versus percutaneous liver biopsy in patients with chronic liver disease: a retrospective single-center study. J Ultrasound 2020;23(2):157-167

21 Bhogal N, Lamb B, Arbeiter B, et al. Safety and adequacy of endoscopic ultrasound-guided random liver biopsy in comparison with transjugular and percutaneous approaches. Endosc Int Open 2020;8(12):E1850-E1854 
124 News

22 Bang JY, Ward TJ, Guirguis S, et al. Radiology-guided percutaneous approach is superior to EUS for performing liver biopsies. Gut 2021;(e-pub ahead of print). doi: 10.1136/gutjnl-2021-324495
23 Samarasena JB, Chang KJ. Endoscopic ultrasound-guided interventions for the measurement and treatment of portal hypertension. Gastrointest Endosc Clin N Am 2019;29(2):31132010.1016/j.giec.2018.12.004 